\title{
INTELLIGENT ROBOTRONICS: HARDWARE-SOFTWARE COMPLEXES OF ROBOTARIUMS
}

\author{
V. E. Pryanichnikov, A. Ya. Ksenzenko, S. V. Kuvshinov, \\ Yu. V. Poduraev, E. A. Prysev, R. V. Helemendik \& S. R. Eprikov
}
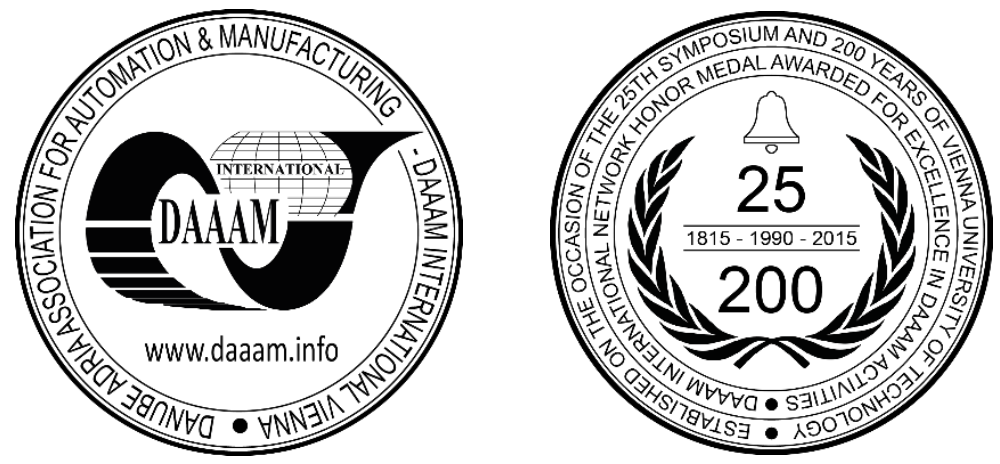

This Publication has to be referred as: Pryanichnikov, V[alentin]; Ksenzenko, A[lexander]; Kuvshinov, S[ergey]; Poduraev, Y[uriy]; Prysev, E[vgeny] \& Khelemendik, R[oman] (2016). Intelligent Robotronics: Hardware-Software Complexes of Robotariums, Proceedings of the 27th DAAAM International Symposium, pp.0225-0229, B. Katalinic (Ed.), Published by DAAAM International, ISBN 978-3-902734-08-2, ISSN 1726-9679, Vienna, Austria DOI: $10.2507 / 27$ th.daaam.proceedings.033

\begin{abstract}
The article describes the technology of development of advanced mobile service robots and basic hardware and software elements as well as their use for implementation of the network of associated laboratories-robotariums within the framework of the project called "Intellectual Robotronics" organized by the Central European Branch of the International Academy of Engineering in conjunction with KIAM of the Russian Academy of Sciences, the International Institute of New Education Technologies (IINET) of the Russian State University for the Humanities, the universities of Russia, Croatia and Austria. Within the framework of this network, the access is provided to the entire range of the developed mechatronic devices and mobile robots having systems for remote charging and video stream exchange, and also to 3Dprototyping tools placed in the participating organizations, and to their guidance papers. Mobile robots and their simulation models repeat the basic functionality and appearance of significantly more difficult and expensive robotic complexes (RTC) of the Ministry of Emergency Situations and other agencies, which allows for the effective conducting of training of the operators of such RTCs and the development of integrating software ("middleware"), creating the knowledge representation technology and automatic generation of action plans.

This paper was partially supported by the Russian Foundation for Basic Research, Project No. 16-07-01264a, 16-0700935a, 16-07-00811a.
\end{abstract}

Keywords: robotarium network; hardware and software simulators of robotic complexes, knowledge representation and pentalogic, intellectual robotronics. 


\section{Introduction}

This article describes the key directions of development of advanced intellectual robotic complexes. The first problem is the need to unify the procedure of embedding various mechatronic devices by creating the respective integrating software. This allows for significant simplification the transfer from the inevitable and expensive building of low-level sensory control systems to the development of the top-level of control systems (CS). The second issue is insufficient development of deductive mechanisms and knowledge representation methods for CS intellectualization.

Solving these problems is difficult due to absence of systematic training of specialists, so-called "knowledge engineers". We have created application-dependent software and hardware complexes - space-distributed robotic laboratories (Fig.1) providing full access to all mechatronic devices included into them remotely through the Internet. This has allowed developing an effective education technology on the basis of the interuniversity network created by the International Institute of New Education Technologies of the Russian State University for the Humanities together with the Institute of Applied Mathematics named after Keldysh of the Russian Academy of Sciences (IAM) and the International Laboratory "Sensorika". As a part of the proposed approach, 10 AMUR mobile robots have been developed and produced with three integrated Robotino mobile robots (including elephant-trunk manipulator made by Festo) and integrated industrial manipulators. We have solved the problems of synchronization, delay time tracking and access rights differentiation. Also, mesh networks with moving repeaters are being built. Implementing the system has allowed to solve education-related problems during laboratory practicums closely related to conducting of timely scientific research studies $[1-7]$.

\section{Developing software and hardware framework and education programs}

The problems we are solving have appeared due to the necessity of remote online reprogramming sensory control systems developed and installed on Brokk-110D and Brokk-330 mobile robots. These robots have been rebuilt to execute operations in dangerous areas with limited access for humans. The customers needed to have possibility to change it during mission execution without stopping robots, to integrate new mechatronic devices and third-party sensors. For this reason, the corresponding remote access tools and multi-camera vision systems have been developed [8, 9].

These results have found the use in AMUR educational and scientific robotic centers [10]. A technology for distribution of control processes has been created on the basis of integrating software ("middleware"), which allows combining hundreds of mechatronic devices with provision of remote access to them, and at the same time, providing dynamic change of system components configuration without stopping robots and automatic switching in case of faults, including auto-configuration. This software supports various operating systems, provides for integrating new drivers for sensors and drives, which can be installed even in field conditions [11]. Data streams were organized as special data structures ("buses"), and the dissection of control tasks into separate processes was the key to success for online collective (parallel) programming and fast prototyping. Teaching students to use this method helps them to avoid one of the problems of modern education related to "tape-record" acquirement of lectures and absence of creativity. The proposed solution of this problem is to motivate students to take part in scientific research studies as "knowledge engineers", to teach them how to build the required algorithms and effective formalizations of tasks [12]. As a base for such training research studies, AMUR mobile robots have been developed, each consisting of a body, track or two wheels (differential drive), or walking mechanisms, TV cameras (from 1 to 6), video-servers, ultrasonic locators (measurable ranges from 50 to 3000 $\mathrm{mm}$ ), odometers, on-board controller, accumulators and charging devices, four analog channels and 16 on/off channels, power keys with PWM and PID controllers 2-10A (12...32V), on-board micro-PC and a remote PC connected through Wi-Fi with maximum range up to 50 meters or 1 kilometer when using additional antennas, and also a TV module for external supervision through WiFi-“satellite" with PTZ (Pan, Tilt, Zoom) and >10x optical zoom. AMUR mobile robots work on Linux in Python and $\mathrm{C}++$ with the use of a distributed technology for programming of all types of sensory and video data processing, with logical filters on the remote PC and/or on board. All data are recorded in real time mode by buses (DTF), which reflect all the details of operation for the last week/month of mobile robots' functioning. DTF buses provide not just recording of data into files, but also synchronization, extrapolation and interpolation of data, which allows avoiding problems of data transmission delays and gaps in data streams, thanks to the respective fast logical filtering. 


\section{TH DAAAM INTERNATIONAL SYMPOSIUM ON INTELLIGENT MANUFACTURING AND AUTOMATION}
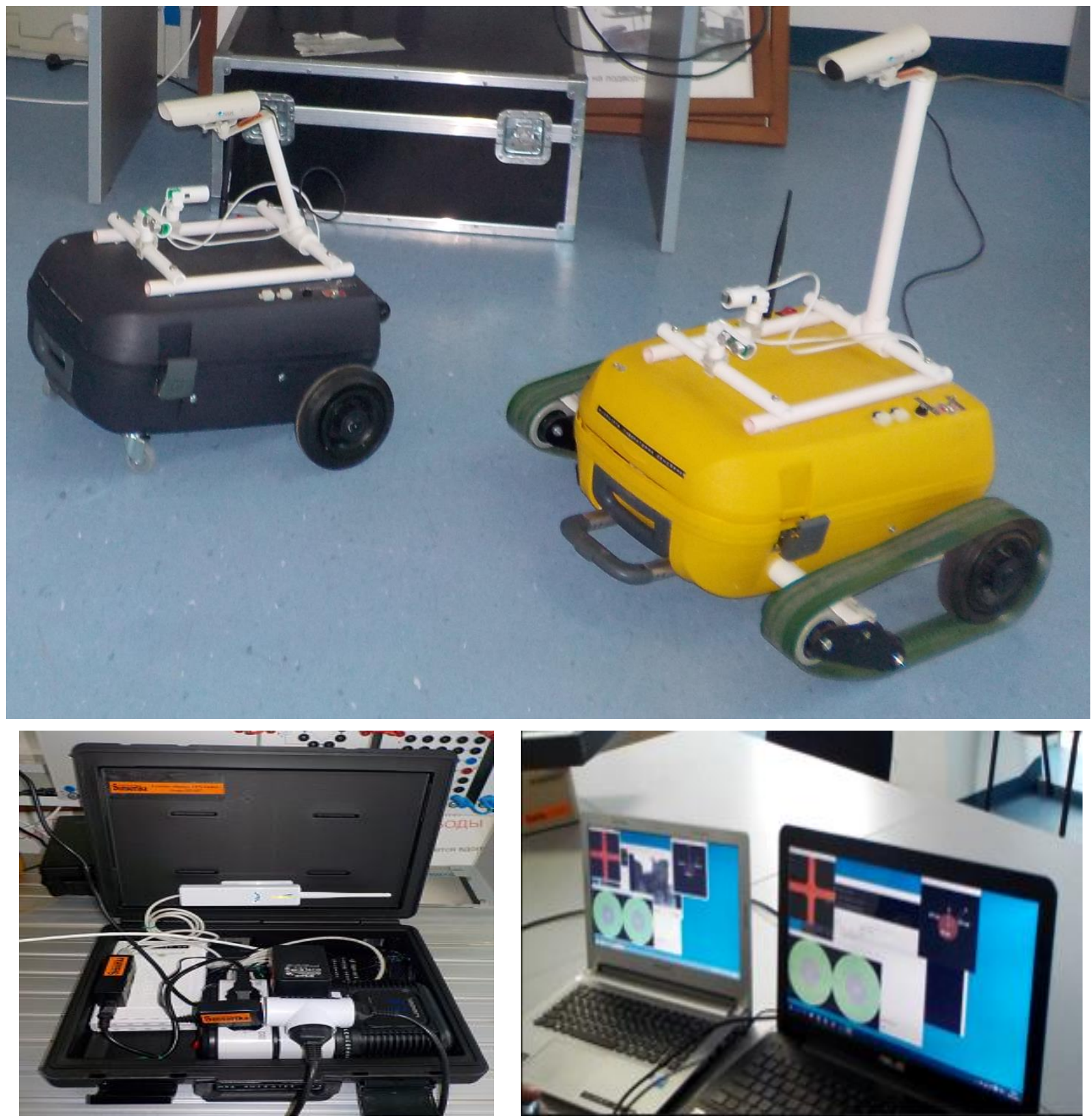

Fig. 1. Complex of AMUR mobile robots. Network forming kit - bottom left. Robot consoles - bottom right

Weight and dimensions of the implemented mobile robots AMUR-5, AMUR-6, AMUR-7, AMUR-105 and AMUR107 are as follows: weight $-17-23 \mathrm{~kg}$, dimensions $-\mathrm{L} 580 x B 510 x H 340 \mathrm{~mm}$. Produced velocity $-10 \ldots 750 \mathrm{~mm} / \mathrm{s}$, battery life $-1-2$ hours.

The main advantage of our approach is the use of our in-house developed simulator or building mathematical models on the basis of V-REP simulator in combination with hinging additional body elements imitating other (more expensive) complexes on the real AMUR mobile robots. This allows performing full-scale training of robot operators with significantly lower expenses by using both the existing models and virtual reality options (Fig. 2). 

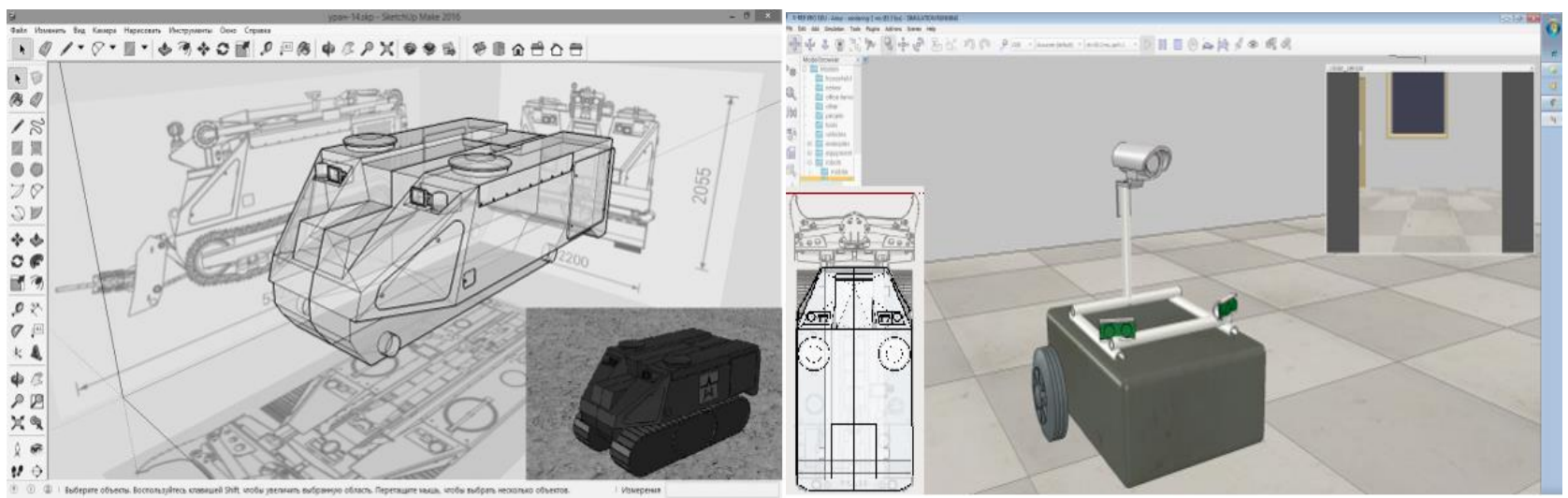

Fig. 2. Virtual mathematical model based on simulation V-Rep

\section{Hardware solutions for contactless power supply}

Contactless power supply system of autonomous robots. One of the discovered solutions, which were used during our research, was the power supply system designed for real-time automatic or semi-automatic recharging of accumulator batteries of mobile robotic devices without using direct connection of electrical contacts (for terrestrial and underwater operating environments.

Applicability of this system as a part of underwater robotic complexes is due to the possibility of performing longcontinuing deep-water operations without lifting robots to the surface for recharging or replacement of on-board accumulator batteries. At that, a set of time-consuming and laborious actions is eliminated: surfacing, unsealing, recharging or battery replacement, subsequent sealing, check of functioning, submersion, and search of the work area. Excluding the necessity to periodically lift the autonomous robot improves the efficiency of underwater works significantly, especially depending on depth (Table 1). Along with recharging, high-speed transmission of data and multichannel video is provided.

Functioning principle of the contactless power supply system is the use of electrodynamic induction. The system consists of two parts: the radiating unit and the receiving unit. The radiating unit includes: converter of electrical energy (generally, direct current) into high-power high-frequency current, and the converter of this current into electromagnetic field radiated in the required direction. The radiating unit is installed on a static or slow-moving part of the robotic complex and has stable guaranteed power supply (Fig.3). The receiving device consists of a receiving antenna, which converts the received electromagnetic oscillation into high-frequency current, and an impedance-matching device, which converts the received energy into normalized direct current with parameters acceptable for normal charging mode of the on-board accumulator of the autonomous robotic device. The receiving device is installed on a fully autonomous robot to be provided with contactless power supply. The main problem in developing such devices is the provision of electromagnetic compatibility of all RTC systems considering the effect of significant electromagnetic radiation, and also the provision of independence and concurrency of processes of on-board battery charging and high-speed data transmission (up to $10 \mathrm{Mbit} / \mathrm{s}$ ).

\begin{tabular}{|l|l|l|}
\hline Characteristic & Underwater robot & Terrestrial robot \\
\hline Distance of efficient energy transmission & $0-20 \mathrm{~mm}$ & $10-30 \mathrm{~mm}$ \\
\hline Received power & $20 \mathrm{~W}$ & $300 \mathrm{~W}$ \\
\hline Efficiency of system & $25-45 \%$ & $20-35 \%$ \\
\hline Input voltage of transmission device & $+48 \mathrm{~V}$ & $\sim 220 \mathrm{~V}$ \\
\hline Weight of receiver & $450 \mathrm{~g}$ & $1800 \mathrm{~g}$ \\
\hline
\end{tabular}

Table. 1. Specifications of the contactless power supply system of underwater and terrestrial autonomous robots 

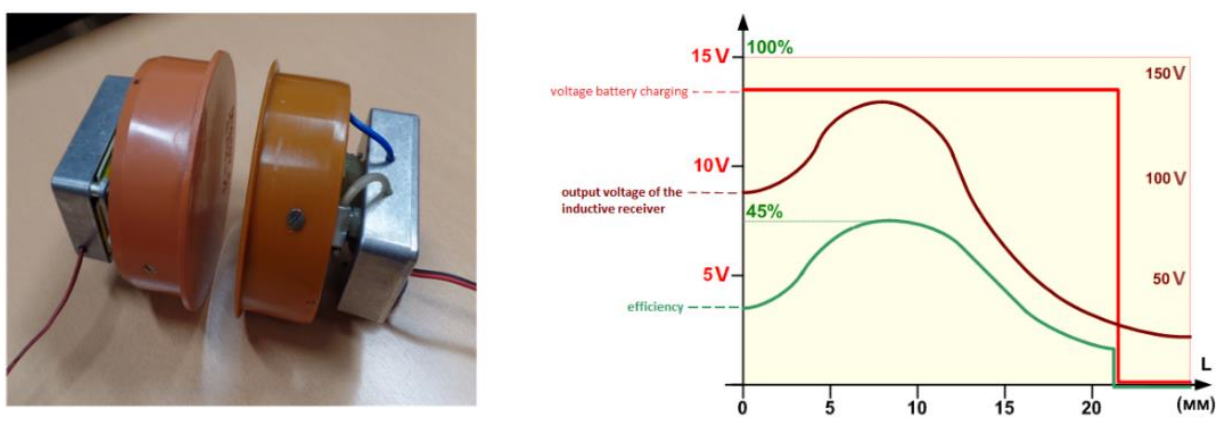

Fig. 3. AMUR-205 mobile robot, contactless power supply and data transmission diagram.

\section{Conclusion}

This article describes the results of studies, which have led to the development of hardware and software that can be used for solving a wide range of mechatronic device control tasks as well as for training tasks. Along with this, if some other solutions are possible for single robots, the proposed approach has almost no alternative as regards to large distributed mobile robotic complexes. The obtained results are being used for optimization of knowledge representation technologies, development of new heuristic methods for intellectualization of robots with advanced abilities, and for building new creative education technologies.

\section{Acknowledgments}

This paper was partially supported by the Russian Foundation for Basic Research, Project No. 16-07-01264a, 16-0700935a, 16-07-00811a.

\section{References}

[1] Pryanichnikov V.E., Biyelich T., Vitsan D., Katalinich B., Kirsanov K.B., Kuvshinov S.V., Marzanov Y.S., Podurayev Y.V., Khelemendik R.V., Prysev E.A., Ugleshik A., Kharin K.V. Development of education technologies and the network of associated laboratories-robotariums. Data Measuring and Control Systems, M.: "Radiotekhnika". 2015, т.13, N7 - ISSN 2070-0814, C.7-25

[2] Pryanichnikov V.E., Andreev V.P. Intellectulazation of special mobile robots, including return algorithm to a zone of stable RC // Proceedings of the XXI Int. Conference on Extreme Robotics. St. Peterburg: Poliectnika-service. 2010. P. 46-49

[3] Pryanichnikov V.E., Andreev V.P., Prysev E.A. Group control of mobile robots, based on the net-technologies // Proceedings of the Int. conference on Robotics for Security \& Space (Planet \& Earth rovers). St. Peterburg: Poliectnika service. 2010. P. 279-283

[4] Katalinic B., Pryanichnikov V.E., Ueda K., Kukushkin I., Cesarec P., Kettler R. Bionic Assembly System: hybrid control structure, working scenario and scheduling // Proceedings of 9th National Congress on Theoretical and Applied Mechanics, Brussels. 2012. P. 111-118

[5] Pyanichnikov V.E. Algorithmic base for remote sensors of mobile robots // Mechatronics, Automation, Control. 2008. № 10(91). P. 10-21

[6] Kirsanov K., Levinsky B., Pryanichnikov V. Integrating software for intelligent robots // Informational-Measuring and Control Systems, Radiotechnika. 2009. V. 7. № 6. P. 35-43

[7] Kirillchenko A.A., Pryanichnikov V.E., Rogozin K.V. Limits of validity and reliability of proofs. Scepticism in mathematics, functions, and traditions // Information-Measuring and Control Systems. 2013. V. 11. № 4. P. 57-65.

[8] Klyuev V.V., Kondrat'ev Yu.A., Okhotsimsky D.E., Popov E.P., Pryanichnikov V.E., et al. Sensor Systems and Adaptive Industrial Robots // monograph: Mashinostroenie. 1985. Ch. 3-5. P. 56-172

[9] Okhotsimsky D.E., Veselov V.A., Platonov A.K., Pryanichnikov V.E. Educational Modular transport robot with PC control // Proceedings of the IV Int. conf. on Flexible production systems. Moscow: Int. R\&D Institute on the Control Problems. 1987. P. 62-64

[10] Andreev V., Kuvshinov S., Pryanichnikov V., Poduraev Yu. Education on the basis of virtual learning robotics laboratory and group-controlled robots // 24th DAAAM International Symposiumon Intelligent Manufacturing and Automation. 2013. Procedia Engineering. 2014. V. 69. P. 35-40

[11] Pryanichnikov V., Andreev V., Bobrov P., Biryukova E., Frolov A., Kharin K., Kirsanov K., Kostin A., Kuvshinov S., Marzanov Y., Prysev E. Scientific-educational distributed laboratory - software and hardware means // Annals of DAAAM for 2012 \& Proceedings of the 23rd International DAAAM Symposium. 2012. V. 23. № 1. DAAAM International. Vienna. Austria. EU

[12] Pryanichnikov V.E., Bielic T., Katalinic B., Kirilchenko A.A., Kirsanov K.B., Khelemendik R.V., Kuvshinov S.V., Marzanov Ju.S., Prysev E.A., Vican D., Uglesic A. Implementation of the main elements of the net of associated laboratories and robotariums - project «Intelligent robotronics»: Sc. Tech. Report\#. 2015-01. Zadar: University of Zadar. Moscow: KIAM Russian Academy of Sciences. 2015. 21p 